\title{
Beyaz Kod Verileri Işı̆̆ında 112 Çalışanlarına Yönelik Şiddet; Retrospektif Değerlendirme
}

\author{
Serap BATI ${ }^{1}$ (I) Hasan KÜÇÜKKENDİRCI ${ }^{2}$ (i) Osman ULUSAL ${ }^{3}$ \\ ${ }^{1}$ Necmettin Erbakan Üniversitesi, Seydişehir Sağlık Bilimleri Fakültesi, Hemşirelik Bölümü, Konya, Türkiye, \\ s.bati@erbakan.edu.tr (Sorumlu Yazar/Corresponding Author) \\ ${ }^{2}$ Necmettin Erbakan Üniversitesi, Meram Tıp Fakültesi, Halk Sağlığı Anabilim Dalı, Konya, Türkiye, \\ kendirci68@hotmail.com
}

${ }^{3}$ T.C. Sağlık Bakanlı̆̆ı, Konya İl Sağlık Müdürlüğü, Konya, Türkiye, osmanulusal@ hotmail.com

\begin{tabular}{|c|c|}
\hline Makale Bilgileri & ÖZ \\
\hline $\begin{array}{l}\text { Makale Geçmişi } \\
\text { Geliş: } 21.10 .2020 \\
\text { Kabul: 30.11.2020 } \\
\text { Yayın: 25.04.2021 } \\
\text { Anahtar Kelimeler: } \\
\text { Beyaz Kod, } \\
\text { Sağlık Çalışanı, } \\
\text { Sağlıkta Şiddet. }\end{array}$ & 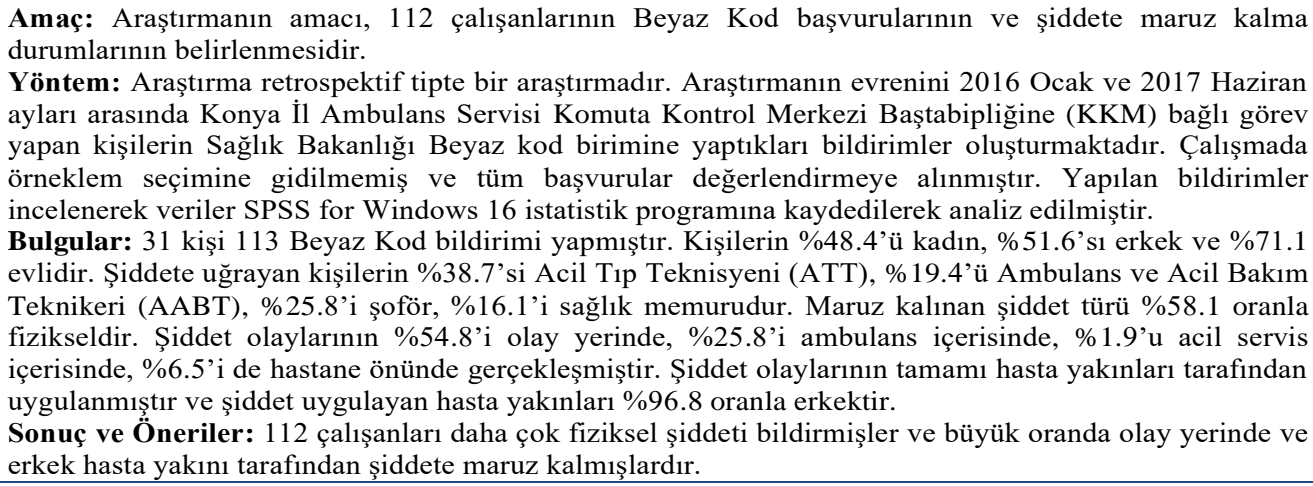 \\
\hline
\end{tabular}

\section{Violence Against 112 Employees in The Light of White Code Data;}

\section{Retrospective Evaluation}

\begin{tabular}{|c|c|}
\hline Article Info & ABSTRACT \\
\hline $\begin{array}{l}\text { Article History } \\
\text { Received: } 21.10 .2020 \\
\text { Accepted: } 30.11 .2020 \\
\text { Published: } 25.04 .2021 \\
\text { Keywords: } \\
\text { White Code, } \\
\text { Health Employee, } \\
\text { Violence in Health. }\end{array}$ & $\begin{array}{l}\text { Purpose: The objective of this study was to determine } 113 \text { White Code applications of } 112 \text { Emergency } \\
\text { Healthcare Professionals and their exposure to violence. } \\
\text { Method: The research was a retrospective study. The population of the study consisted of the } \\
\text { notifications of the personnel employed at Ambulance Service Command and Control Center (CCC) } \\
\text { Office of Chief Physician in Konya province between January } 2016 \text { and June } 2017 \text {. The selection of the } \\
\text { samples was not applied in this study and all applications were considered. The collected data were } \\
\text { analyze by SPSS software. } \\
\text { Results: } 31 \text { individuals announced } 113 \text { White Code notifications. Among them, } 48.4 \% \text { were female, } \\
51.6 \% \text { were male, and } 71.0 \% \text { of them stated that they were married. It was seen that } 38.7 \% \text { of people that } \\
\text { exposed to violence were ECT (Emergency Care Technician), } 19.4 \% \text { were AECT (Ambulance and } \\
\text { Emergency Care Technician), } 25.8 \% \text { were drivers and } 16.1 \% \text { were Medical Assistants. The } 58.1 \text { of } \\
\text { exposed violence types reported by participants were physical and } 41.9 \% \text { were verbal. The employees } \\
\text { stated that } 54.8 \% \text { of the violence took place at the scene, } 25.8 \% \text { in the ambulance, } 12.9 \% \text { in the } \\
\text { emergency department and } 6.5 \% \text { in front of the hospital. All of the violence cases }(100 \% \text { ) were } \\
\text { committed by patient relatives that } 96.8 \% \text { of them were male. } \\
\text { Conclusions and Suggestions: Employees of } 112 \text { Emergency Health Services reported that physical } \\
\text { violence is more prevalent. Also, they stated that they were most exposed to violence at the scene by male } \\
\text { patient relatives. }\end{array}$ \\
\hline
\end{tabular}

Atıf/Citation: Batı, S., Küçükkendirci, H., \& Ulusal, O. (2021). Beyaz kod verileri 1şığında 112 çalışanlarına yönelik şiddet; retrospektif değerlendirme, Genel Sağlık Bilimleri Dergisi, 3(1), 1-8. 


\section{GíRIŞ}

Şiddet, güç veya kudret kullanarak başka bir kişiye, kendine yaralanma ve kayıp ile sonlanan ya da sonlanma olasılığı olan, fiziksel ve ruhsal yönden zarar vermek olarak tanımlanabilir. Dünya Sağlık Örgütü'nün (DSÖ) tanımına göre fiziksel ve sözel zarar verme, psikolojik, cinsel, rrksal taciz olarak belirtilmiştir (Durak vd., 2014). İş yeri şiddeti ise "çalışanın göreviyle ilgili kişi veya kişiler tarafından fiziksel ve psikolojik olarak taciz edildiği, saldırıya uğradığı olaylar” olarak tanımlanabilmektedir (Ayrancı, Yenilmez, Günay ve Kaptanoğlu, 2002).

Son yıllarda toplumun her kesiminde artarak devam eden şiddet özellikle iş yerlerinde belirgin şekilde görülmeye başlanmış, tüm meslek gruplarını etkileyen ciddi bir halk sorunu haline gelmiştir. Sağlık çalışanları diğer hizmet sektörlerinde görev yapanlara oranla iş sağlığı ve güvenliği açısından daha riskli bir gruptur. Karşılaştıkları başlıca riskler; kesici-delici alet yaralanmaları, kas-iskelet sistemi hastalıkları, alerjik hastalıklar, kimyasal ve biyolojik riskler, fiziksel ve psikolojik şiddet olarak özetlenebilir (Kavuncubaşı, 2010).

Literatürde, şiddet olgusunun en çok sağlık alanında ortaya çıktığı ve diğer hizmet sektörlerine göre sağlık çalışanlarının 16 kat daha fazla şiddete maruz kalmakta oldukları belirtilmektedir. Gerek ülkemizde gerekse de dünya genelinde sağlık sektöründeki şiddet oranları giderek artmakta ve önemli bir mesleki risk oluşturmaktadır (Atan ve Dönmez 2011).

Yapılan çalışmalar; sağlık çalışanlarının çalıştıkları süre boyunca en az bir kez herhangi bir şiddet türüne maruz kaldığını, şiddet türünün ise en çok sözel şiddet olduğunu göstermiştir (Acik vd., 2008; Çelebi, 2016; Eğici ve Öztürk, 2018; Esen ve Akyal, 2020; Gormley, Crowe, Bentley ve Levine, 2016). Cinsiyet açısından bakıldığında kadın çalışanların erkeklere oranla daha yüksek oranda şiddete maruz kaldığı görülmüştür (Ayrancı vd., 2006; Acik vd., 2008; Rufen, Günaydın ve Mazı, 2018). Mesaisinin neredeyse tamamını dışarıda geçiren, beklenmedik bir kaza ve hastalanma durumlarında kriz niteliğinde bir soruna sahip olan hastalara müdahale eden 112 Acil Sağlık Çalışanları diğer sağlık çalışanlarına göre daha dezavantajlı bir gruptur (Doğanay, 2014).

Hastane öncesi acil sağlık hizmetleri çalışanları, hastalık, kaza durumlarında olay yerine giderek tıbbi hizmeti başlatan ekiplerdir. ATT (Acil tıp teknisyeni), AABT (Ambulans ve acil bakım teknikeri=paramedik), hemşire, sağlık memuru, sürücü bu ekibin içerisinde yer alan meslek gruplarıdır. Bu hizmet hızlı karar vermeyi, hızlı hareket etmeyi gerektirmektedir. Çoğu zaman meraklı bakışlara odak olmakta ve kişilerin eleştirilerine maruz kalmaktadırlar. Mesai saatlerinin neredeyse tamamında sağlık kurumları dışında hizmet vermektedirler. Bu da hastane öncesi acil sağlık hizmetleri çalışanlarını diğer sağlık çalışanlarına göre iş sağlığı ve güvenliği açısından daha fazla dezavantajlı bir grup haline gelmektedir (Yildırım ve Gerdan, 2017).

2012 y1lında Sağl1k Bakanlığı tarafından çıkarılarak yürürlüğe giren yönetmelikte şiddete uğrayan sağlık personellerine yapılacak olan hukuki yardımın usul ve esasları belirlenmiştir. Bu kapsamda Sağlık Bakanlığı "Beyaz Kod" uygulamasına geçmiştir. Bu uygulama kapsamında Sağlık Bakanlığı merkez biriminde 7/24 hizmet veren 113 Beyaz Kod Çağrı Merkezi kurulmuş ve www.beyazkod.saglik.gov.tr internet adresi oluşturulmuştur.

Yönetmelik sonrasında uygulamadaki aksaklıkları gidermek ve işleyişi açıklamak üzere 2016 yılında yine Sağlık Bakanlığı tarafından "Hukuki Yardım ve Beyaz Kod Genelgesi” yayınlanmıştır. Genelgede sağlık kuruluşlarında gerçekleşen bütün şiddet olaylarının bildirimlerinin Beyaz Kod sistemi üzerinde yapılması istenmiştir. Bu amaç ile oluşturulmuş olan 113 beyaz kod çağrı merkezi ve internet adresine ek olarak kurumlar içerisinde şiddet olayı bildirimleri ile ilgili birimler oluşturulmuştur. Kurum bazında şiddet olaylarının takibi bu birimlere verilmiştir. 
Yönetmelik ve genelgeye göre şiddet olayları bildiriminde işleyiş şu şekildedir:

- Sağlık Bakanlığı hukuk müşavirliği bünyesinde Beyaz Kod Çağrı Merkezi kurulmuştur. Bu çağrı merkezinde gelen çağrılar karşılanır ve beyaz kod sistemine kayıtları yapılır.

- Sağlık Bakanlığına bağlı kuruluşlarda beyaz kod ile ilgili işlemler Çalışan Hakları ve Güvenliği birimlerince yürütülür. $\mathrm{Bu}$ birimlerde kişilerin şikâyetçi olup olmadığına bakılmaksızın kurumlarına gerçekleşen şiddet olaylarının tümünün sisteme kaydı yapılır. Başvuruya ilişkin bilgi ve belgeler toplanarak onların da sistem girişi gerçekleştirilir.

• Her ilde İl Sağlık Müdürlüğü bünyesinde "Beyaz Kod İl Koordinatörlüğü” kurulur. Koordinatörlüğe il sağlık müdürü tarafından görevlendirilen bir avukat başkanlık eder. Bu birim tarafından il bazında sisteme girişleri yapılmış olan başvuruların beyaz kod kapsamında olup olmadıkları değerlendirilir. Beyaz kod kapsamında olduğuna karar verilen başvurular ile ilgili evraklar savcılığa intikal ettirilir. Mağdur personele hukuki yardımda bulunulur.

Literatürde işyerinde herhangi bir şiddet türüne maruz kalmış kişilerin stres, depresyon gibi ruhsal problemler yaşadıkları ve kaygı düzeylerinin arttığı belirtilmektedir (Al, Zengin, Derya, Gökçen, Yılmaz ve Yıldırım, 2012; Atan ve Dönmez, 2011; Çelebi, 2010). Kayg1 düzeylerindeki artış bireylerin özel hayatlarında, aile yaşantılarında da yaşadıkları sorunların artmasına neden olmaktadır (Gökçe ve Dündar, 2008). Şiddete maruz kalmış kişilerde yaşadıkları ruhsal problemler ek olarak ayrıca; bel, baş, boyun, mide ağrıları, kalp hastalıkları ortaya çıkmaktadır. Ayrıca yapılan araştırmalar, işyerinde şiddete maruz kalma durumu çalışanların, işlerinden tatmin düzeylerinin düşmesine, kurumdan ayrılma düşüncelerinin artmasına (Hershcovis, 2009) ve iş kazalarına daha sıklıkla maruz kalmalarına neden olmaktadır (Hintikka, 2010).

Bu araştırmanın amacı, 112 Acil Sağlık çalışanlarının 113 Beyaz Kod başvurularının ve şiddete maruz kalma durumlarının belirlenerek idari ve hukuki tedbirlerde farkındalık oluşturmaktır.

\section{YÖNTEM}

\section{Araştırma Modeli}

Araştırma retrospektif tipte bir araştırmadır.

\section{Örneklem}

Araştırmanın evrenini Ocak 2016 ve Haziran 2017 ayları arasında Konya İl Ambulans Servisi Komuta Kontrol Merkezi (KKM) Baştabipliğine bağlı görev yapan kişilerin Sağlık Bakanlığı 113 Beyaz kod birimine yaptıkları bildirimler oluşturmaktadır. Belirtilen tarihler arasında 31 Beyaz kod başvurusu gerçekleşmiştir. Örneklem seçimine gidilmemiş olup tüm başvurular değerlendirmeye alınmıştır.

\section{Veri Toplama Araçları ve Süreçleri}

Araştırmanın verileri 113 Beyaz Kod birimine yapılan bildirimler incelenerek elde edilmiştir. Veri toplama aracı kişilerin sosyo-demografik verileri ve uğranılan şiddet ile ilgili bilgileri içeren iki bölümden oluşmaktadır.

\section{Verilerin Analizi}

Elde edilen veriler SPSS Programına kaydedilerek değerlendirilmiştir. Veriler bilgisayar ortamına aktarıldıktan sonra hata kontrolleri yapılmış, ortalama, standart sapma ve yüzde olarak özetlenmiştir.

\section{Etik}

Çalışmamız Helsinki Deklarasyonu prensiplerine uygun olarak yapılmıştır. Araştırmanın amacı katılımcılara açıklanarak yazılı onamları alınmıştır. 


\section{BULGULAR}

Ocak 2016-Haziran 2017 tarihleri arasında toplam 31 kişi 113 Beyaz Kod bildirimi yapmıştır. Kişilerin \%48.4'ü kadın, \%51.6'sı erkektir ve \%71.0'i evli olduğunu ifade etmiştir. Ortanca yaşları 33.0 (Min:23, Max:55), kurumda ortama çalışma süreleri ise ortalama 7.1 y1l olarak bulunmuştur. Kişilerin meslek grubuna göre dağglımlarına bakıldığında; \%38.7'si ATT, \%19.4'ü AABT, \%25.8'i şoför, \%16.1'i sağlık memuru olduğu görülmektedir (Tablo 1).

Tablo 1. Çalışmaya Katılan Kişilerin Sosyo-Demografik Verileri

\begin{tabular}{|c|c|c|c|}
\hline & DEMOGRAFİK DEĞİSTENLER & $\mathbf{n}$ & $\%$ \\
\hline \multirow{2}{*}{ Cinsiyet } & Kadın & 15 & 48.4 \\
\hline & Erkek & 16 & 51.6 \\
\hline \multirow{3}{*}{$\begin{array}{l}\text { Medeni } \\
\text { Durum }\end{array}$} & Evli & 22 & 71.0 \\
\hline & Bekar & 9 & 39.0 \\
\hline & ATT & 12 & 38.7 \\
\hline \multirow{3}{*}{$\begin{array}{l}\text { Meslek } \\
\text { Grubu }\end{array}$} & $\mathrm{AABT}$ & 6 & 19.4 \\
\hline & Şoför & 5 & 16.1 \\
\hline & Sağlık Memuru/Hemşire & 8 & 25.8 \\
\hline \multirow{5}{*}{$\begin{array}{l}\text { Eğitim } \\
\text { Durumu }\end{array}$} & Ortaokul & 3 & 9.7 \\
\hline & Lise & 14 & 45.1 \\
\hline & Önlisans & 11 & 35.5 \\
\hline & Lisans & 3 & 9.7 \\
\hline & Toplam & 31 & 100.0 \\
\hline
\end{tabular}

Kişiler maruz kalınan şiddet türünü fiziksel ve sözlü olarak \%58.1, \%41.9 ise sözlü şiddet olarak bildirmişlerdir. Şiddet olaylarının \%54.8'inin olay yerinde, \%25.8'inin ambulans içerisinde, \%12.9'unun acil servis içerisinde, \%6.5'inin hastane önünde gerçekleştiğini ifade etmişlerdir. Gün içerisinde şiddet \%61,3 oran 16-24 saatleri arasında gerçekleşmiştir. Şiddet \%100 olarak hasta yakınları ve \%96.8 oranla erkekler tarafından uygulanmıştı (Tablo 2).

Tablo 2. Maruz Kalınan Şiddet Türü, Yeri ve Şiddeti Uygulayan Kişi Cinsiyetine Göre Dağılımı

\begin{tabular}{llcc}
\hline & & $\mathbf{n}$ & $\mathbf{\%}$ \\
\hline \multirow{2}{*}{ Şiddet Türü } & Sözlü & 13 & 41.9 \\
& Fiziksel+Sözlü & 18 & 58.1 \\
\multirow{2}{*}{ Olay Yeri } & Olay Yeri & 17 & 54.8 \\
& Ambulansı̈n İçi & 8 & 25.8 \\
\multirow{2}{*}{ Şiddeti Uygulayan Kişinin } & 2 & 6.5 \\
Cinsiyeti & Hastane Önü & 4 & 12.9 \\
& Acil Servis İçerisi & 1 & 3.2 \\
& Kadın & 30 & 96.8 \\
& Erkek & $\mathbf{3 1}$ & $\mathbf{1 0 0 . 0}$ \\
\hline
\end{tabular}

\section{TARTIȘMA}

Tüm meslek grupları içerisinde, zor durumdaki bireylere doğrudan teması gerektiren sağlık bakım sektöründe çalışanlara yönelik şiddet oranlarındaki artış ülkemizde ve dünyada giderek daha dikkat çekici hale gelmekte ve medyaya yansıyan sağlık çalışanlarına şiddet olayları her geçen gün daha da artmaktadır. Sağlık çalışanları, diğer iş alanlarındaki meslek gruplarına göre şiddet herhangi bir şiddet türüne maruz kalma açısından 16 kez daha fazla risklidirler (Çelebi, 2016).

Çalışmamızın sonuçlarına göre; 113 Beyaz Kod bildirimi yapan kişilerin \%51.6'sı kadın, \%48.4’ü erkekler oluşturmakta kişilerin \%58.1'i hem sözlü hem de fiziksel şiddete maruz kaldıklarını bildirmişlerdir. ABD'de acil tıp teknisyenlerinin yaralanmalarını tespit etmek amacı ile yapılan bir çalışmada, çalışma sırasında 530 saldırı bildirildiğini ve bu bildirimlerin \%27'sini kadın çalışanlar oluşturduğu tespit edilmiştir (Maquire ve Smith, 2013). 
Polat ve Çırak (2019) bir eğitim araştırma hastanesinde 2016-2018 yılları arasındaki 345 beyaz kod bildirimini inceledikleri çalışmalarında 312 sözel şiddet, 31 sözel ve fiziksel şiddet ve iki fiziksel şiddet olgusu tespit etmişlerdir. Şiddete maruz kalan personelin \%63.18 kadın olduğu görülmüştür.

2016 yılında 1789 acil tıp teknisyeni ile yapılan bir çalışmada \%67'sinin sözlü, \%46.3’ünün fiziksel şiddete maruz kaldığı bulunmuştur (Mirinda, Remple, Melissa ve Levine, 2016). Tayvan'da yapılan bir çalışmada çalışanların \%74.3'ünün sözlü, \%49.3'ünün fiziksel şiddete maruz kaldığı tespit edilmiştir (Wang, Fang, Wu, Hsu ve Lin, 2019). İran'da yapılan çalışmada katılımcıların \%75'i anketi doldurmadan önceki 12 ay içinde en az bir tür şiddete maruz kaldığını bildirmiş ve şiddet türünün \%71 oranında sözlü, \%38 oranında fiziksel saldırı olduğunu ifade etmişlerdir (Rahmani, Hassankhani, Mills ve Dadashzadeh, 2012). Konya ilinde bir kamu hastanesinde meydana gelen ve başvurusu yapılan 68 beyaz kod bildirim formlarını retrospektif olarak inceledikleri çalışmalarında; sağlık çalışanlarının maruz kaldığı şiddet türünün en çok sözel şiddet (56) olduğunu tespit etmişlerdir. Maruz kalınan şiddet türünü sözel şiddetten sonra sırası ile fiziksel şiddet (8), kamu malına zarar verme (1) izlemiş̧ir (Rufen vd., 2018). Belirtilen çalışmalarda kişilerin maruz kaldığı sözel şiddet oranı bu çalışmaya oranla daha yüksektir. Çalışmamız sadece bildirimi yapılan şiddet olaylarını içermektedir. Orandaki düşüklüğün sebebi, kişilerin sözel şiddeti bildirmeme eğiliminde oldukları ile ilişkilendirilmiştir.

Çalışmamızda uğranılan şiddet \%100 oran ile hasta yakınları ve \%96.8 oran ile erkekler tarafından gerçekleştirilmiştir. İstanbul ilinde görev yapan hastane öncesi acil sağlık hizmetleri çalışanlarının iş ile ilgili maruz kaldıkları yaralanmalarını belirlemek üzere yapılan çalışmada, çalışmaya katılanların \%72'sinin hasta yakınları tarafından sözel, \%39.82'inin fiziksel şiddete maruz kaldığını tespit etmişlerdir (Gülen vd., 2014). Çanakkale ili Acil Sağlı Hizmetleri İstasyonlarında görev yapan kişiler ile yapılan bir çalışmada katılımcıların \%74.1'inin sözlü şiddet, \%11.2'sinin fiziksel şiddetle karşılaştığını belirtmiştir. Kişiler şiddet uygulayanların \%73.7'sinin hasta/yaralı yakını, \%18.2'inin hasta/yaralanın kendisi olduğunu ifade etmiştir (Çelebi, 2016). Konya ilinde yapılan bir çalışmada, şiddeti uygulayanların cinsiyet dağılımı incelendiğinde; erkeklerin (53) kadınlardan daha fazla (19) olduğunu görmüşlerdir (Rufen vd., 2018).

Tokat ilinde beyaz kod birimlerine yapılan bildirimleri inceledikleri çalışmalarında; mağdurların $\% 50.7$ 'sinin erkek, şiddete maruziyet nedeniyle en fazla beyaz kod bildirimi yapan meslek grubunun hekimler (\%64.2), şiddetin en sık (\%85.8) yaşandığı yeri hastaneler olarak bulmuşlardır. Şiddet olaylarının \%94.8'inde hakaret, \%39.6'sında tehdit, \%12.7'sinde fiziksel şiddet ve \%0.7'sinde yaralanma olduğu saptamışlardır (Gülpınar vd., 2019). Akbaş ve ark (2014) yaptıkları çalışmalarında katılımcıların \%99.7'sinin 112'de çalışırken şiddete maruz kaldığını bulmuşlardır. Çalışmada uğradıkları şiddet türü \%99 sözel, \%64 fiziksel, \%64.2 oranla ise hem sözel hem de fiziksel şiddet olarak belirtilmiştir. Çalışmamızda en çok beyaz kod bildirimi yapan meslek grubunun ATT'ler ve şiddetin en sık yaşandığı yerin ise olay yeri olduğu görülmektedir.

Esen ve Akyal (2018) bir eğitim ve araştırma hastanesindeki beyaz kod başvurularını inceledikleri çalışmada \%94.5 sözel şiddet vakası meydana geldiği tespit etmişlerdir. Aynı çalışmada şiddet olaylarının \%62.1'i mesai içerisinde, \%60.7'sinin hastalar tarafından uygulandığı, şiddete maruz kalan sağlık çalışanlarının yaş ortalamasının 39.5 olduğunu bulmuşlardır. Bizim çalışmamızda ise şiddetin sıklıkla uygulandığı saat 16-24 olarak bulunmuştur.

112 Acil Sağlık Hizmetleri çalışanları güvenlik donanımından yoksun bir şekilde çalışmakta, vakanın bulunduğu ortamı ve ne ile karşılaşacaklarını bilmemektedirler. Nitekim şiddete maruz kalınan yer olarak büyük oranla olay yeri olarak bildirilmiştir.

112 çalışanları daha çok fiziksel şiddeti bildirmiş̧ler ve büyük oranda olay yerinde ve erkek hasta yakını tarafından şiddete maruz kalmışlardır. Olay yerinde 112 çalışanlarının güvenliğine ilişkin alınan önlemlerin arttırılması, yasal ve politik düzenlemelerin gözden geçirilmesi ve toplumun bu konuda eğitilerek bilinçlendirilmesinin şiddet oranlarında azalmaya neden olacağı düşünülmektedir.

Literatürde 112 personelinin şiddete maruz kalma durumu oldukça yüksek olmasına rağmen 113 Beyaz Kod sistemine bildirim oranı oldukça düşüktür. Bunun nedeninin kişilerin sistemin işleyişini bilmemesi, şikâyette 
bulunma ve dava süreci aşamalarındaki devam eden güvenlik sorunu ve işleyiş ile ilgili prosedürler ile uğraşmak istememesi gibi sebeplerden kaynaklandığ 1 düşünülmektedir. Verilen eğitimlerde bildirimin önemi vurgulanarak farkındalığın artırılması sağlanmalıdır.

\section{Finansal destek}

Finansal destek alınmamışır.

\section{Çıkar Çatıșması}

Herhangi bir çıkar çatışması yoktur.

\section{Yazar Katkıları}

Tasarım/Design: S.B.; Veri Toplama veya Veri Girişi Yapma/Data Collection or Processing: O.U.; Analiz ve Yorum/Analysis or Interpretation: S.B.; Literatür Tarama/Literature Search: H.K.; Yazma/Writing: S.B.

\section{KAYNAKÇA}

Acik, Y., Deveci S.E., Günes, G., Gulbayrak, C., Dabak, S., Saka, G., Vural, G., Can, G., Bilgin, N.G., Dündar, P.E., Erguder, T., \& Tokdemir, M. (2008). Experience of workplace violence during medical speciality training in Turkey. Occupational Medicine, 58(5), 361-366. https://doi.org/10.1093/occmed/kqn045

Al, B., Zengin, B., Derya, Y., Gökçen, C., Yılmaz, D.A., \& Yıldırım, C. (2012). Increased violence towards health care staf. The Journal Of Academic Emergency Medicine, 11, 115-24. https://doi:10.5152/jaem.2012.033

Atan, Ş.Ü., \& Dönmez, S. (2011.) Hemşirelere karşı işyeri şiddeti. Adli Tlp Dergisi, 25(11), 71-80. https://www.journalagent.com/adlitip/pdfs/ADLITIP_25_1_71_80.pdf

Ayrancı, Ü., Yenilmez, Ç., Günay, Y., \& Kaptanoğlu, C. (2002). Çeşitli sağlık kurumlarında ve sağlık meslek gruplarında $\begin{array}{llllll}\text { şiddete uğrama sıklığı. } & \text { Anadolu } & \text { Psikiyatri } & \text { Dergisi, } & 3(3), & \text { 147-154. }\end{array}$ https://app.trdizin.gov.tr/publication/paper/detail/TVRZNE5EYzM

Ayrancı, Ü., Yenilmez, Ç., Balcı, Y., \& Kaptanoğlu, C. (2006). Identification of violence in Turkish health care settings. Journal of Interpersonal Violence, 21, 276-296. https://doi.org/10.1177/0886260505282565

Çelebi, İ. (2016). Çanakkale 112 acil sağlık hizmetleri istasyonlarında görev yapan sağlık çalışanlarının şiddetle karşılaşma durumu ve bu durumun tükenmişlik sendromu üzerine etkisi. Hastane Öncesi Dergisi, 1(2), 1-13. https://dergipark.org.tr/tr/download/article-file/253560

Doğanay, İ. (2014). Alo 113-Beyaz Kod: Acil sağlık hizmetlerinde çalışan sağlık personelinin yaşadığı şiddet olgusu ve çözüm önerileri. Sağllk Akademisyenleri Dergisi, 1 (2), 136-140. https://dergipark.org.tr/en/download/article-file/752356

Durak, T. Ç., Yolcu, S., Akay, S., Demir, Y., Kılıçaslan, R., Değerli, V., \& Parlak, İ. (2014). Bozyaka Eğitim ve Araştırma Hastanesi sağlık çalışanlarına hasta ve hasta yakınları tarafından uygulanan şiddetin değerlendirilmesi. Genel Tip Dergisi, 24 (4), 130-137. https://www.geneltip.org/upload/sayi/86/GTD-00746.pdf

Eğici, M.T., \& Öztürk, G.Z. (2018). Beyaz kod verileri ışı̆̆ında sağlık çalışanlarına yönelik şiddet. Ankara Med J, 2, 224-31. https://doi:1017098/amj.436537

Esen, H., \& Akyal, G. (2020). Sağlık kurumlarında yaşanan şiddetin değerlendirilmesi: eğitim ve araştırma hastanesi örneği. Sağlık Akademisyenleri Dergisi, 7(1), 1-9. https://dergipark.org.tr/en/download/article-file/1018813

Gormley, M.A., Crowe, R.P., Bentley, M.A., \& Levine, R. (2016). A national description of violence toward emergency medical services personnel. Prehospital Emergency Care, 20(4), 439-447. https://doi:10.3109/0903127.2015.1128029.

Gökçe, T., \& Dündar, C. (2008). Samsun ruh ve sinir hastalıkları hastanesinde çalışan hekim ve hemşirelerde şiddete maruziyet sıklı̆̆ ve kayg1 düzeylerine etkisi. İönü Üniversitesi Tip Fakültesi Dergisi, 15(1),25-28. https://arastirmax.com/tr/system/files/dergiler/5674/makaleler/15/1/arastirmax-samsun-ruh-sinir-hastaliklarihastanesinde-calisan-hekim-hemsirelerde-siddete-maruziyet-sikligi-kaygi-duzeylerine-etkisi.pdf

Gülen, B., Serinken, M., Hatipoğlu, C., Özaşır, D., Sönmez, E., Kaya, G., \& Akpınar, G. (2016). Workrelated injuries sustained by emergency medical technicians and paramedics in Turkey. Ulusal Travma Acil Cerrahi Dergisi, 22(2), 14549. https://doi:10.5505/tjtes.2015.94224

Gülpınar, S., Bulut, Y.E., \& Çıtıl, R. (2019). Retrospective evaluation of white code based files in Tokat province between 2012 and 2014. TJFMPC, 13(2), 142-150. https://doi:10.21763/tjfmpc.569497

Hershcovis, M.S., \& Barling, J. (2009). Towards a multi-foci approach to workplace aggression: A meta-analytic review of outcomes from different perpetrators. Journal of Organizational Behavior, 31, 24-44. https://doi:10.1002/job.621

Hintikka, N., \& Saarela, K.L. (2010). Accidents at work related to violence-analysis of finnish national accident statistics database. Safety Science, 48, 517-525. https://doi.org/10.1016/j.ssci.2009.12.024 
Kavuncubaşı, Ş. (2010). Hastane ve Sağllk Kurumları Yönetimi, Siyasal Kitabevi.

Maguire, B., \& Smith, S. (2013). Injuries and fatalities among emergency medical technicians and paramedics in the united states. Prehospital and Disaster Med, 28(4), 1-7. https://doi.org/10.1017 / S1049023X13003555

Mirinda, A.G., Remple, P.C., Melissa, A.B., \& Levine, R. (2016). A national description of violence toward emergency medical services personnel. Prehospital Emergency Care, 20(4), 439-447. https://doi.org/10.3109/10903127.2015.1128029

Polat, Ö., \& Çırak, M. (2019). Sağlıkta şiddetin beyaz kod verileri ile değerlendirilmesi. Bakırköy Tıp Dergisi, 15, 393-8. https://doi.org/10.4274/BTDMJB.galenos.20190918115436

Rahmani, A., Hassankhani, H., Mills, J., \& Dadashzadeh, A. (2012), Exposure of Iranian emergency medical technicians to workplace violence: A cross-sectional analysis. Emergency Medicine Australasia, 24 (1), 105-110. https://doi.org/0.1111 / j.1742-6723.2011.01494.x

Rufen, O., Günaydın, H., \& Mazı, M.İ. (2018). Çalışan hakları ve güvenliği birimlerinin işleyişi ile beyaz kod başvurularının retrospektif olarak değerlendirilmesi (Konya İli Örneği). Sağllk Akademisyenleri Dergisi, 5(2), $142-153$. https://dergipark.org.tr/tr/download/article-file/640405

T.C. Sağlık Bakanlığı (2016). Hukuki Yardım ve Beyaz Kod Uygulaması Genelgesi (2016/3).

Wang, P.Y., Fang, P.H., Wu, C.L., Hsu, H.C., \& Lin, C.H. (2019). Workplace violence in Asian emergency medical services: a pilot study. Int. J. Environ. Res. Public Health, 16(20), 3936. https://doi.org/10.3390/ ijerph16203936

Yıldırım, S.A., \& Gerdan S. (2017). Hastane öncesi acil sağlık çalışanlarının iş sağlığı ve güvenliği kapsamındaki mesleki riskleri. Hastane Öncesi Dergisi, 2(1), 37-49. https://dergipark.org.tr/tr/download/article-file/304508 


\section{EXTENDED ABSTRACT}

Introduction: The 112 emergency healthcare professionals, who spend almost all of their shifts outside the hospital and encounter with a crisis-like problem such as unexpected accidents and illness, are more at risk than other healthcare professionals. A law that was issued by the Ministry of Health and executed in 2012, has defined the procedures and principles of legal assistance for healthcare professionals who may expose to violence. The Ministry of Health has activated the "White Code" application in this regard. One hundred and thirteen White Code Call Centers serving 24/7 have been established in the central unit of the Ministry of Health; and the website of "www.beyazkod.saglik.gov.tr" was created within the scope of this application. The aim of this study was to increase the awareness of administrative and legal authorities through the determination of 113 White Code applications of 112 Emergency Healthcare Professionals and their exposure to violence.

Materials and Methods: The research was a retrospective study. The population of the study consisted of the notifications of the personnel employed at Ambulance Service Command and Control Center (CCC) Office of Chief Physician in Konya province between January 2016 to June 2017. No sample was taken and all applications were evaluated. The research data was obtained through the examination of notifications to 113 White Code units. The collected data were evaluated by SPSS software. The consent of individuals who were involved in the study was obtained before the study.

Findings: Totally, 31 individuals announced 113 White Code notifications between January 2016 and June 2017. Among them, $48.4 \%$ were female, $51.6 \%$ were male, and $71.0 \%$ of them stated that they were married. The median age of the participants was 33.0 (Min: 23, Max: 55) years; their average employment period in the institution was 7.1 years. When distribution of people according to their profession group was evaluated, we found that $38.7 \%$ were ECT (Emergency Care Technician), 19.4\% were AECT (Ambulance and Emergency Care Technician), $25.8 \%$ were drivers, and $16.1 \%$ were Medical Assistants. The $58.1 \%$ of the violence types reported by participants were physicaland $41.9 \%$ were verbal violence. They stated that $54.8 \%$ of the violence took place at the scene, $25.8 \%$ in the ambulance, $12.9 \%$ in the emergency department and $6.5 \%$ in front of the hospital. It was detected that $61.3 \%$ of all violence occurred during the day, between 4 p.m. to 12 a.m. $100 \%$ of the violence was committed by patients relatives, and $96.8 \%$ of them were male.

Discussion: This study aimed to assess the frequency of exposure of violence in emergency health personel. Our result is consistent with other studies. For example, Mirinda et al. (2016) found that $67 \%$ of the participants were exposed to verbal violence and $46.3 \%$ of them were exposed to physical violence on 1,789 emergency medical technicians. Also, Wang et al. (2019) found that $74.3 \%$ of the employees were exposed to verbal violence and $49.3 \%$ to physical violence in Taiwan. In another similar studies in Turkey, Gülen et al. (2014) found that $72 \%$ of the participants were exposed to verbal violence and $39.82 \%$ were exposed to physical violence by the relatives of the patients on work-related injuries of emergency healthcare personnel who were employed in Istanbul. Also, Çelebi (2016) stated that $74.1 \%$ of participants experienced verbal violence and $11.2 \%$ faced physical violence in individuals employed in Emergency Health Services Stations in Çanakkale province. They also stated that $73.7 \%$ of the perpetrators were relatives of patients/victims, but $18.2 \%$ were patients/victims themselves. Besides, Akbaş et al. (2014) found that $99.7 \%$ of the participants were exposed to violence while they were working at 112 Emergency Services. The violence types were stated as verbal (99\%), physical violence (64\%), and both verbal and physical violence $(64 \%)$. It was stated in the same study that the violence rate committed by patient relatives was $57.5 \%$ and $59.5 \%$ of attackers were male. Regarding the gender of the person, Eğici et al. (2018) found that $55 \%$ of the victims of violence were female and the average age of the healthcare personnel exposing to violence was 32.36 years. Their result regarding the age average was similar to our study. Rufen et al. (2018) in a retrospective study on 68 white code notifications in a public hospital within Konya province found that the most common type of violence applied to healthcare personnel was verbal violence $(n=56)$. This was followed by physical violence $(n=8)$, then damage to public property $(n=1)$, following verbal violence. When the distribution of the violence type according to gender was considered, it was found that female healthcare personnel aswas exposed to violence twice as much as male healthcare personnel. On the other hand, when the gender distribution of violence perpetrators was reviewed, it was found that male $(n=53)$ attackers were more prevalent than female attackers $(\mathrm{n}=19)$.

Conclusion and Suggestions: Employees of the 112 Emergency Health Services usually work without security equipment. They do not know the environment of the incident and what they may encounter. According to our result, the most common violent place was reported as the crime scene. Employees of 112 Emergency Health Services reported physical violence more, and they were most exposed to violence at the scene by male patient relatives. It is thought that increasing the precautions taken for the safety of 112 employees at the scene, reviewing the legal and political regulations, and raising the awareness of the society through mass media may lead to a decrease in the violence rates. Although 112 personnel's exposure to violence is quite high in the literature, the reporting rate of the 113 White Code system is quite low. The reasons for this are considered as unawareness of the employees about the system, unwillingness to deal with the ongoing security problem at the stages of the litigation process, and filing a complaint and the procedures related to the operation. Awareness should be increased by emphasizing the importance of notification system by training. 